Short Communication

\title{
One Step Preparation of Superhydrophobic Surface on Copper Substrate with Anti-Corrosion and Anti-Icing Performance
}

\author{
Hong $\mathrm{Li}^{1,2, *}$, Yanfeng $\mathrm{Lu}^{1}$, XinYan Zou ${ }^{1}$, Chunyu Wang ${ }^{1}$, Hongyan Wei ${ }^{1}$ \\ ${ }^{1}$ School of Physics and Electronic Information, Huaibei Normal University, Huaibei, 235000, PR \\ China \\ ${ }^{2}$ Schoo Key Laboratory of Green and Precise Synthetic Chemistry and Applications, Ministry of \\ Education; Huaibei Normal University, Huaibei, Anhui 235000, P. R. China \\ *E-mail: lihonggreat@126.com
}

doi: $10.20964 / 2020.11 .16$

Received: 30 June 2020 / Accepted: 5 August 2020 / Published: 30 September 2020

\begin{abstract}
Copper stearate coating was fabricated on a copper substrate through a simple solution immersion method at room temperature. The surface exhibited grass-like structure, which endowed it with superhydrophobicity and the water contact angle was about $152.3^{\circ}$. Electrochemical measurement revealed that this superhydrophobic surface (SHS) showed better corrosion resistance than bare copper surface and the inhibition efficiency of this SHS was about 95.91\%. Moreover, the SHS demonstrated the reduction in adhesion between ice and surface, thus allowing for easy removal of ice. This method may provide a simple way to design SHS with corrosion resistance and anti-icing performance on metal surfaces.
\end{abstract}

Keywords: Copper stearate coating; Corrosion resistance; Electrochemical measurement; Anti-icing

\section{FULL TEXT}

(C) 2020 The Authors. Published by ESG (www.electrochemsci.org). This article is an open access article distributed under the terms and conditions of the Creative Commons Attribution license (http://creativecommons.org/licenses/by/4.0/). 